\title{
The role of spiritual leadership on empowering employees: A case study of educational system
}

\author{
Amir Hossein Amir Khani ${ }^{\mathrm{a}}$, Hassan Darvish ${ }^{\mathrm{a}}$, Kamal Miandari $^{\mathrm{a}}$ and Hossein Sotudeh Arani ${ }^{\mathrm{b}^{*}}$
}

${ }^{a}$ Assistant Professor , Department of Economic ,Management and Accounting, Payame Noor University 19395-4697,Tehran, Iran ${ }^{c}$ Management Group, Payame Noor University, Tehran, Iran

CHRON I C L E ABSTRACT

Article history:

Received October 14, 2012

Received in revised format

26 December 2012

Accepted 10 January 2013

Available online

January 122013

Keywords:

Empowering

Payame Noor university

Spiritual leadership

\begin{abstract}
Empowering employees play essential role on increasing the productivity of any business units. In this paper, we present an empirical investigation to study the impact of spiritual on empowering employees of Payame Noor university in city of Tehran, Iran. The study uses two benchmark questionnaires to examine the hypotheses of this survey. There are seven subhypotheses associated with this study including the relationship between empowering employees from one side and vision, friendship, faith to work, being meaningful, organizational membership, organizational commitment and performance feedback. The results of implementation of structural equation modeling confirmed all sub-hypotheses except commitment.
\end{abstract}

(C) 2013 Growing Science Ltd. All rights reserved.

\section{Introduction}

These days, all organizations attempt to use various techniques to empower their human resources. There are literally various factors influencing empowering organizations such as faith, sense of friendship, etc. Azad and Sadeghi (2012) performed an empirical study to determine effective factors on organizational commitment. They discussed that organizational commitment is considered as an important component of organization on the success of business units. Many firms rely on their employees and when some skilled employees leave an organization, tremendous chaos in some organizations could appear and they reported that four factors influencing organizational commitments. The first one was cultural factor, the second issue was human resource based factors while the third one was associated with the behavior-based factors and finally empowering based factors were the last item. The study used structural equation modeling and the results indicated that the third factor, behavior based components, was the most important factor followed by the second factor, human resource factor. They also concluded that the third important factor was cultural issues followed by empowering factors. Abtahi and Saadi (2012) investigated the impact of structural

*Corresponding author.

E-mail addresses: sotudeh_h@yahoo.com (H. Sotoudi Arani) 
factors on empowering employee in banking sector. They selected 1859 employees who work in 11 different areas of an Iranian bank and discussed the finding associated with two departments of engineering and administration. Using a standard questionnaire, they gathered the necessary information and the results were validated using Cronbach Alpha and factor analysis. They implemented five different regression techniques to analyze the data and independent variables included complexity, formality and concentration. In addition, the dependent variables included selfeffectiveness, self-organization, meaningful, self-acceptance and trust. Their results indicated that there was no correlation among structural components in engineering and administration areas.

Sadati (2012) performed a survey relation of organizational culture and organizational citizenship behavior with employees' empowerment. He studied the relationship between organizational culture and organizational citizenship behavior (OCB) with employees' empowerment. They discussed four dimensions of employees' empowerment including meaningfulness, choice, competence and impact are investigated and identified four dimensions for organizational culture including adaptability, consistency, involvement and mission. Hamidi et al. (2012) explained that human resources are the primary sources of building advanced technological enterprises in today's world and any improvement in productivity of human resources plays essential effect on empowering employees. They used a hybrid of Burda and DEMATEL to detect important factors for improving manpower productivity. They used DEMATEL technique to detect cause and effect factors and propose a linear programming technique to detect important factors impacting productivity improvement. According to Beikzad et al. (2012), empowering workers play an important role on increasing productivity in any organization. The service industries such as insurance firms or banks mostly rely on their own people to keep their customers and incomes. They presented an empirical study to detect the most influential factors empowering bank employees. The results were analyzed using statistical tests and descriptive methods and reported that leadership, academic qualification, appropriate policy and strategy, cooperation and processes played important role on empowering and enabling bank's employee.

\section{The proposed study}

The proposed study of this paper considers the impact of five different CQ on performance of banking sector. Fig. 1 demonstrates the framework of this study.

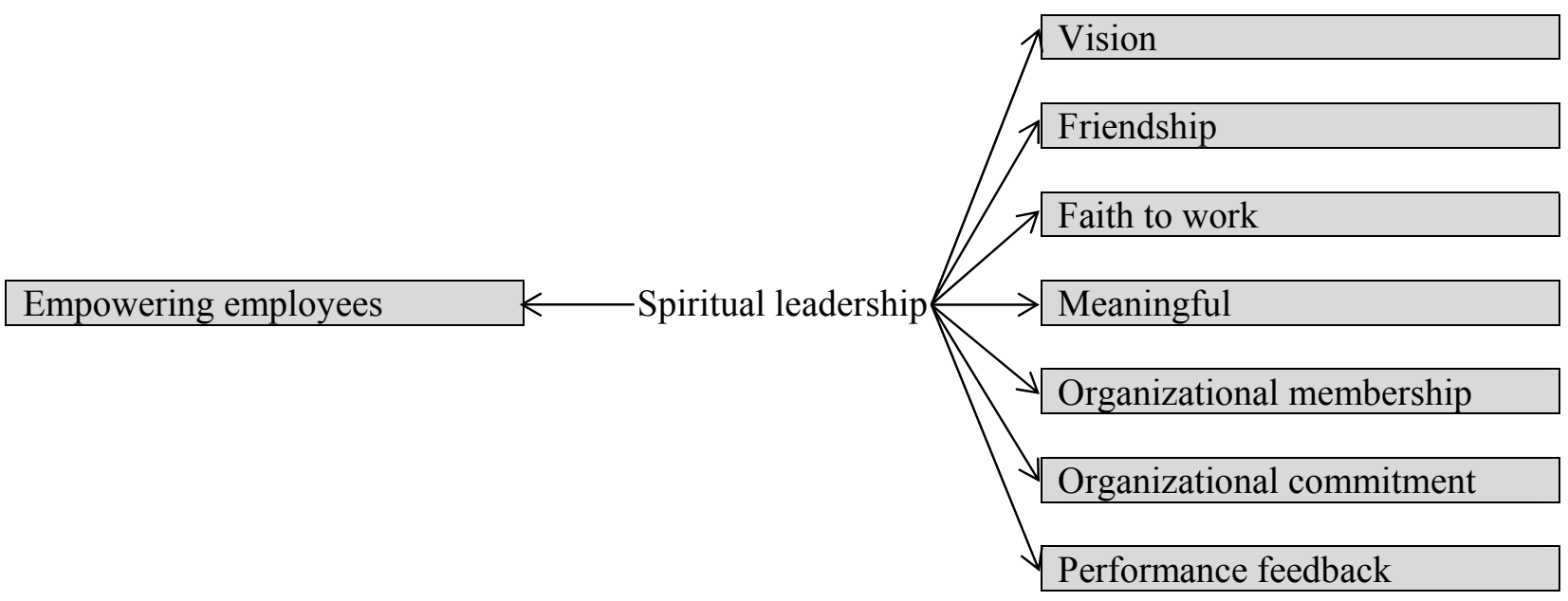

Fig. 1. Structure of the proposed study

As we can observe from the proposed study demonstrated in Fig. 1, there are seven hypotheses associated with the proposed study of this paper as follows, 
1. Organizational vision could empower employees.

2. Friendship empowers employees.

3. Faith to work empowers employees.

4. Feeling meaningful empowers employees.

5. Organizational membership empowers employees.

6. Organizational commitment empowers employees.

7. Performance feedback empowers employees.

The proposed study of this paper is accomplished among employees of Payame Noor University located in Iran where there were approximately 250 managers and employees. We use the following formula to calculate the minimum number of sample size,

$$
n=\frac{N \times z_{\alpha / 2}^{2} \times p \times q}{\varepsilon^{2} \times(N-1)+z_{\alpha / 2}^{2} \times p \times q},
$$

where $N$ is the population size, $p=1-q$ represents the yes/no categories, $z_{\alpha / 2}$ is CDF of normal distribution and finally $\varepsilon$ is the error term. Since we have $p=0.5, z_{\alpha / 2}=1.96$ and $N=250$, the number of sample size is calculated as $n=180$. The proposed study of this paper distributes 220 questionnaires among employees. The study also distributes a standard questionnaire consists of 25 questions among them to measure the performance of the same employees.

In our survey, $110(50 \%)$ people only finished a 2-year university college program, 78 (35.5\%) finished bachelor degree, $22(10 \%)$ hold master degree of science and $10(4.5 \%)$ maintained master degree of science. In terms of the participants' age, $58(26.4 \%)$ were younger than 30, $80(27.3 \%)$ were between 30 to 39 years of age, $62(28.2 \%)$ were between 40 to 49 years of age and $20(18.2 \%)$ of the participants were older than 50. Fig. 2 shows the participants' years of experiences, gender and marital status.

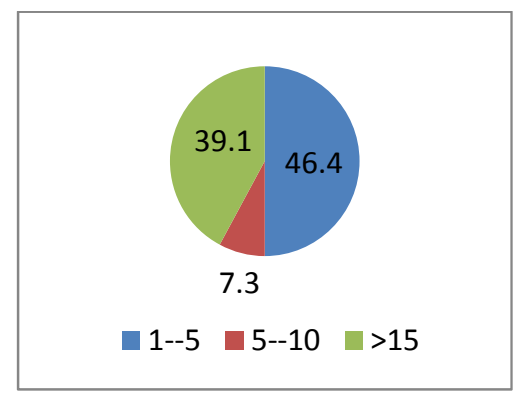

Fig. 2. (a) Job experience

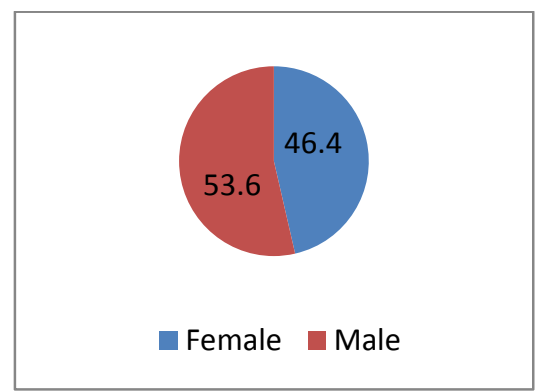

Fig. 2. (b) Gender

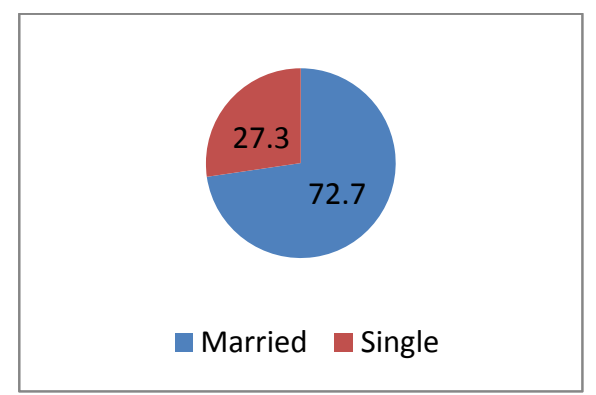

Fig. 2. (c) Marital status

Fig. 2. Personal characteristics of the participants

As we can observe from the results of Fig. 2, nearly half of the participants had between one to five years of job experience and nearly, two third of the participants were married and there is a good diversity one people who participated in our survey in terms of their genders. All questions are designed in Likert scale and Table 1 demonstrates details of the questions. 


\section{Table 1}

The questions of the survey on spiritual leadership questions

\begin{tabular}{|c|c|c|c|c|}
\hline & Perspective & Question & Value & t-student \\
\hline 1 & Vision & I am committed to the vision of the organization. & 0.87 & 15.14 \\
\hline 2 & Vision & Organizational vision motivates me to work harder. & 0.85 & 14.64 \\
\hline 3 & Vision & I believe the organizational vision to employees. & 0.35 & 4.87 \\
\hline 4 & Friendship & My organization cares about employees & 0.72 & 10.87 \\
\hline 5 & Friendship & My firm is kind and treats employees gently when they make mistake. & 0.83 & 10.73 \\
\hline 6 & Friendship & My organization keeps employees' information confidential. & 0.14 & 1.86 \\
\hline 7 & Friendship & My organization does not punish unintentional mistakes. & 0.27 & 3.73 \\
\hline 8 & Friendship & Leaders in my organization are honest. & 0.48 & 6.78 \\
\hline 9 & Friendship & Leaders in my organization have the capability to be honest. & 0.20 & 2.67 \\
\hline 10 & Faith & I choose challenging tasks for my organization since I faith to firm. & 0.45 & 6.58 \\
\hline 11 & Faith & I do anything for the success of the organization since I faith to firm. & 0.88 & 15.35 \\
\hline 12 & Faith & I work hard for my organization because of my faith to organization. & 0.84 & 14.33 \\
\hline 13 & Meaningful & My tasks are important for me to do. & 0.98 & 19.95 \\
\hline 14 & Meaningful & My duties play important role in my life. & 0.00 & 20.63 \\
\hline 15 & Meaningful & The tasks I accomplish are increasingly meaningful for me. & 0.67 & 11.24 \\
\hline 16 & Membership & I feel my organization understands me well. & 0.85 & 4.40 \\
\hline 17 & Membership & I think my firm appreciates what I am doing. & 0.12 & 1.83 \\
\hline 18 & Membership & My impression is that my leaders strongly pay attention to me. & 0.28 & 3.10 \\
\hline 19 & $\begin{array}{l}\text { Organizational } \\
\text { commitment }\end{array}$ & I think I am part of a family in my organization. & 0.86 & 15.38 \\
\hline 20 & $\begin{array}{l}\text { Organizational } \\
\text { commitment }\end{array}$ & I feel happy to spend the rest of my life in this organization. & 0.79 & 13.45 \\
\hline 21 & $\begin{array}{l}\text { Organizational } \\
\text { commitment }\end{array}$ & I talk to my friends about this organization as a good place to work. & 0.83 & 14.64 \\
\hline 22 & $\begin{array}{l}\text { Organizational } \\
\text { commitment }\end{array}$ & I have a feeling that my organization troubles are my own problems. & 0.87 & 15.64 \\
\hline 23 & Performance feedback & $\begin{array}{l}\text { Anyone in this organization is busy with his/her tasks and there is less } \\
\text { time to be wasted. }\end{array}$ & 0.57 & 4.86 \\
\hline 24 & Performance feedback & In this organization, quality is in high priority. & 0.50 & 6.95 \\
\hline 25 & Performance feedback & In this organization, anyone works hard. & 0.95 & 7.34 \\
\hline
\end{tabular}

In addition, in our questionnaire, there are other questions associated with empowering employees, which are summarized in Table 2 as follows,

\section{Table 2}

The questions of the survey on empowering employees' questions

\begin{tabular}{llcl}
\hline & Question & Value & t-student \\
\hline 26 & I have the ability to do anything I want. & 0.69 & 11.27 \\
27 & I am free to make my own decision. & 0.75 & 12.81 \\
28 & I believe I have the ability to do things. & 0.20 & 2.93 \\
29 & I believe I have the ability to influence others. & 0.78 & 13.39 \\
30 & I am empowering other members in organization. & 0.58 & 9.16 \\
31 & I have a good background about my own responsibilities & 0.78 & 8.82 \\
32 & I believe working in this organization is an opportunity for me to increase my capabilities. & 0.65 & 10.47 \\
33 & I have the opportunity to influence on others. & 0.63 & 10.01 \\
34 & I think I am doing different things. & 0.72 & 12.04 \\
35 & I believe I am good in what I am doing. & 0.80 & 14.03 \\
36 & I am confident on what I am doing. & 0.42 & 6.32 \\
37 & I have confident to my own capabilities. & 0.80 & 14.05 \\
38 & I know the skills for accomplishing my tasks well. & 0.48 & 6.78 \\
39 & I feel I have independency on accomplishing various tasks. & -0.24 & -3.40 \\
40 & I could not do anything from the skills I learnt. & -0.03 & -0.35 \\
41 & I think the stuffs I have learnt are useful to my responsibilities. & 0.37 & 5.50 \\
\hline
\end{tabular}

In order to validate the questionnaire, we have distributed 30 questions among participants and Cronbach alpha (Cronbach, 1951) are calculated for the first questionnaire given in Table 1 has been calculated as 0.893 and for the second one given in Table 2 is equal to 0.806 , respectively. Cronbach 
alpha for vision, faith, friendship, membership with three questions were $0.710,0.677,0.878,0.589$, respectively. In addition, Cronbach alpha was 0.906 for organizational commitment with four questions and it was 0.810 for performance feedback. We have also consulted with some professionals about the content of the questions and tried to make sure about the validity of them.

\section{The results}

In this section, we present details of our findings on testing different hypotheses. We first look at correlations among various factors using Pearson correlation ratios. Table 3 demonstrates the results of our findings,

Table 3

The results of Pearson correlation ratios

\begin{tabular}{lllllllll}
\hline & Empowering & Vision & Friendship & Faith & Meaningful & Membership & Commitment & Productivity \\
\hline Empowering & 1 & & & & & & & \\
$\quad$ Vision & 0.581 & 1 & & & & & & \\
Friendship & 0.368 & 0.739 & 1 & & & & & \\
Faith & 0.516 & 0.285 & 0.206 & 1 & & & \\
Meaningful & 0.121 & 0.030 & 0.123 & 0.182 & 1 & & \\
Membership & 0.339 & 0.401 & 0.696 & 0.137 & -0.109 & 1 & & \\
Commitment & 0.284 & 0.086 & 0.428 & 0.093 & 0.002 & 0.598 & 1 & \\
Productivity & 0.009 & 0.017 & 0.375 & -0.043 & 0.095 & 0.482 & 0.700 & 1 \\
\hline
\end{tabular}

As we can observe from the results of Table 3, there are some strong positive correlations between friendship and mission (0.739), between productivity and commitment (0.700), between membership and friendship (0.696) and between commitment and membership (0.598). In addition, there are some positive correlations between commitment and friendship (0.428), between faith and vision (0.285), between faith and friendship (0.206). Finally, there are some sort of positive relationships between meaningful and faith (0.182), between meaningful and empowering (0.121). We have applied structural equation modeling (SEM) to study the relationship between different components. Fig. 2 shows the results of our survey. As we can observe from the results of Fig. 3, there is a meaningful relationship between spirituality and empowering employees $(\gamma=10)$. Therefore, the main hypothesis of the study has been confirmed. There are also some meaningful relationships between spirituality and vision, friendship, faith, meaningful, membership and productivity, which means the hypotheses $1,2,3,4,5$ and 7 have been confirmed. However, our survey does not find any conclusion that there is any relationship between spirituality and commitment. Table 4 shows the summary of our findings for testing the main and seven sub-hypotheses.

\section{Table 4}

The results of testing the main and sub-hypotheses

\begin{tabular}{lccc}
\hline Hypothesis & Standard coefficient & $\gamma$ & Result \\
\hline Main: There is a meaningful relationship between spirituality and empowering. & 1.03 & 10 & $\sqrt{ }$ \\
1. There is a meaningful relationship between vision and empowering. & 0.83 & 10.01 & $\sqrt{ }$ \\
2. There is a meaningful relationship between friendship and empowering. & 0.65 & 7.66 & $\sqrt{ }$ \\
3. There is a meaningful relationship between faith and empowering. & 0.79 & 8.83 & $\sqrt{ }$ \\
4. There is a meaningful relationship between meaningful and empowering. & 0.62 & 7.32 & $\sqrt{ }$ \\
5.There is a meaningful relationship between membership and empowering. & 0.42 & 3.50 & $\sqrt{ }$ \\
6.There is a meaningful relationship between commitment and empowering. & -0.03 & -0.42 & $\times$ \\
7.There is a meaningful relationship between performance feedback and empowering. & -0.53 & -6.00 & $\sqrt{ }$ \\
\hline
\end{tabular}

\section{Conclusion}

In this paper, we have studied the impact of spiritual on empowering employees of Payame Noor university in city of Tehran, Iran. The study gathered two benchmark questionnaires to investigate the hypotheses of this survey. There was one main hypothesis, which associated with the relationship between empowering employees and spiritual leadership and the study confirmed this relationship. In 
addition, there were seven sub-hypotheses including the relationship between empowering employees from one side and vision, friendship, faith to work, being meaningful, organizational membership, organizational commitment and performance feedback. The results of implementation of structural equation modeling confirmed all sub-hypotheses except commitment.

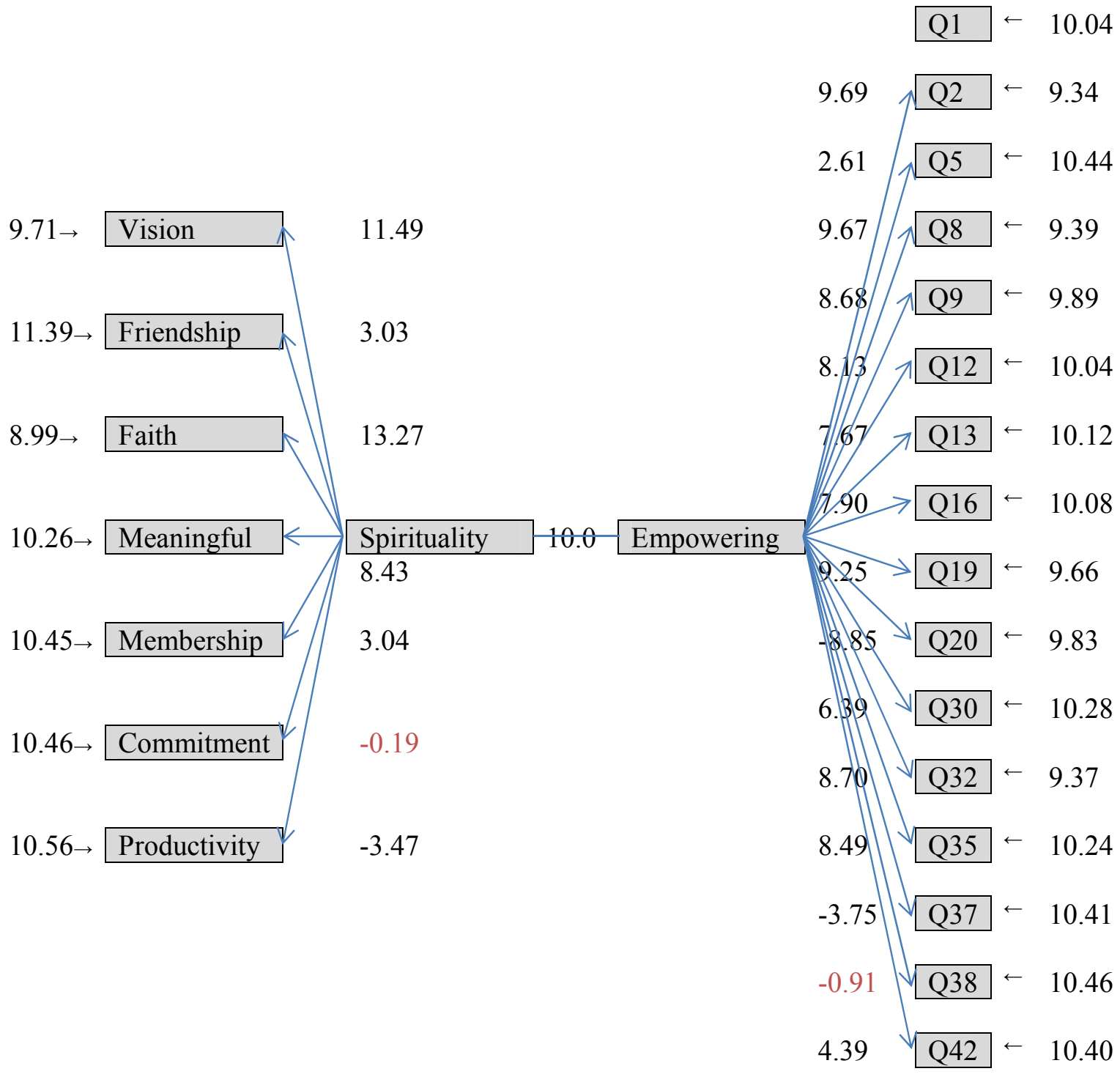

Fig. 3. The results of implementation structural equation modeling

\section{References}

Abtahi, S.H., \& Saadi, M.R. (2012). A conceptual model for empowering bank's human resources: A case study of Tejarat bank of Iran. Management Science Letters, 2(3), 979-988.

Azad, A. \& Sadeghi, S. (2012). An empirical study to determine effective factors on organizational commitment. Management Science Letters, 2(8), 2981-2986.

Beikzad, J., Majnooni Totakhaneh, Y., \& Ghorbannejad Maleki, S. (2012). An empirical study on empowering private bank workers using EFQM. Management Science Letters, 2(1), 321-328.

Cronbach, L. J. (1951). Coefficient alpha and the internal structure of tests. Psychometrika, 16(3), 297-334.

Hamidi, N., Yousefi, P., Rahimi, A., Jabari, F. (2012). A hybrid of Borda and DEMTEL for productivity improvement. Management Science Letters, 2(8), 2757-2764.

Sadati, S.E. (2012). A survey relation of organizational culture and organizational citizenship behavior with employees’ empowerment. Management Science Letters, 2(6), 2175-2186 